\title{
Challenges and prospects of using information technologies in higher education
}

\author{
Alexander Frolov ${ }^{1, *}$ \\ ${ }^{1}$ Moscow Technological Institute, 199334, Moscow, Russia
}

\begin{abstract}
The considerable attention is paid to information technologies in system of the higher education now. Using the latest technology, software and hardware in the learning process allows achieving high outcomes quality of study. The article deals with modern teaching technologies, including distance learning technology, case-technology, which is already used in practice in higher education. There remain unresolved issues of effective use of new learning technologies, the quality of the used software and hardware. The perspective directions of development of informatization of education are defined.
\end{abstract}

\section{Introduction}

Development of information technologies is a priority task of modern society in recent years. In modern conditions the learning process is in constant interaction with new information complexes and systems which allow introducing new methods and approaches in an education system.

Certainly, the development of information technology entails exploring new opportunities for the practical use in the system of higher education of recent achievements in the field of informatics. Implementation of new information technologies in the educational environment, as well as any other innovative process, makes changes in pedagogical sphere. Process of informatization of education is aimed at creating more comfortable conditions, both for work of the teacher, and for training of the student. The special attention in this process is paid to interaction of the teacher and student. The new technologies integrated into an education system allow due to new approaches in learning to direct and realize the potential of future expert. One of the most important tasks is the development of the student's personality, the formation of skills and abilities to develop a strategy to address both instructional and professional tasks. New technologies help to achieve increase in students' creative thinking. Through the new opportunities the student becomes more motivated to resolving of the task set for him.

The introduction of new information technologies and the development of new information systems in the education system has become a factor of dynamic development of world science [1]. It is important to understand a role of informatization of system of the higher education in the modern world where information technologies have to find reflection in educational and methodical complexes and programs of the higher education. It is important to pay attention to system of retraining of experts and advanced training programs of the experts working in an education system. First of all we are talking about teachers. The understanding of the teacher when using of modern technologies is necessary by him in concrete situations of educational process. There are two main directions of informatization of education system. One direction corresponds to unmanaged informatization. Unmanaged informatization is carried out at the initiative of the teacher. Such informatization is directed to improvement of the most actual, according to the teacher, aspects of educational process. Another direction affects the managed informatization of the education system. This type of informatization is supported by material resources and according to the general principles possesses the concept and the program [2].

Use of information technologies in the education system can have the different directions of their application. So at the present stage of development of the teacher has the opportunity to use the new technology at almost every stage of the educational process. Information technology can be used in the preparation of the theoretical material, when developing information and methodological support of discipline, when developing demonstration materials for classes, at examination of students, for collecting and the analysis of statistics of progress of learning.

\section{Research and discussion}

As basic elements of informatization of learning it is necessary to allocate three components:

- information technology;

- the software allowing to use these technologies;

Corresponding author: a frolov@mti.edu.ru 
- hardware by means of which technologies are put into practice.

One of the most perspective and promptly developing technologies in recent years is the technology of distance learning. Distance learning represents a complex of educational services. Educational services in this technology are provided by means of the specialized educational environment. The structure of such educational environment is made by information technologies and transmission media of data, hardwaresoftware and organizational and methodical providing. Distance learning allows carrying out interactive communication between the student and the teacher without their direct meeting. There is an opportunity to independently develop a certain massif of knowledge of the chosen program.

The technology of distance learning is aimed at the development in the student of abilities to independent thinking due to special educational methods and technologies. Stimulation of intellectual activity and maintenance of high motivation to obtaining new skills and knowledge is reached due to establishment of specific goals of educational process and involvement of the student in him. The special approach in distance education system gives efficiency to learning. Material to students is presented in the structured form that allows gaining the systematized knowledge of each subject of learning.

The main problem in system of distance learning consists in involvement of the student in educational process. It is obvious that the technology of distance learning is built by such methods and ways of learning that meet the modern telecommunications environment. In this regard there is a problem to make of the student not of the passive consumer of information provided in the course of learning, and the active participant of this process.

Considerable development was gained in recent years by the concept of "gamification" of distance learning. This concept is based on use of game mechanisms, the principles and tools for the solution of real, non-gaming tasks and challenges, in the most different areas of public life. However, in the application of this technology lies the problem of establishing a framework of student involvement in the learning process. Excessive enthusiasm for formal game aspects of learning can have an adverse effect on development of materials of the studied discipline [3].

Besides the technologies considered earlier, there are also other modern technologies used in learning. It is necessary to refer technology of conference communication to the proved modern information technologies. In educational process the technology of conference communication has great opportunities; application of this technology allows solving a number of the tasks arising in the course of learning. By means of a videoconference there is an opportunity to give remote classes, thereby having given an opportunity to the teacher or the expert not to go to personal meeting with trained. This technology allows saving the teacher's time, gives the chance to bigger quantity trained to gain knowledge in short terms. At implementation of research activity of the colleague from different geographic locations have an opportunity to work on one project, spending a minimum of time for personal meetings. The technology of conference communication in the modern world in the conditions of limited opportunities for personal meetings and business trips allows concentrating attention on educational process [4].

One of the new learning technologies is the case technology. In an education system this technology is used relatively recently, however, she is already recognized as many experts of one of the most effective in the learning process. Such type of distance learning technology based on use in educational process of specially developed complex of the multimedia and audiovisual educational and methodical materials given to students for independent work at interaction and consultations with the teacher. Case method is carried out in several stages. At the first stage learners are offered to get acquainted with case materials independently. The second stage assumes work in a group where conducted research of the case, clarification of a problem situation and coordination of the solution of a problem situation. At the third stage the general discussion of the entire group of learning is provided, results of the proposed solutions are analyzed. When using the case method the student reveals his ability to analyze, because the problem is not presented in open form, the problem needs to be defined independently. The main advantage a case technology consists in a combination of a theoretical and practical side of the studied question that positively affects formation of professional knowledge and skills of future expert.

The technologies considered above are already used to some extent in an education system. The youngest technology in the Russian education system is the MediaWiki technology. This technology provides new opportunities for each participant of pedagogical community in the sphere of interaction and the organization of the information and education environment. It should be noted that the MediaWiki technology is used only by certain higher educational institutions. There is a range of questions which need to be finished in this technology. The main problem areas of MediaWiki technology are lack of personification of tasks and lack of a possibility of control over the implementation of tasks. Developments on elimination of defects of this technology are conducted; there is a gradual expansion of borders of application of the MediaWiki technology in Russia.

Another component of the informatization of education system is software. The modern teacher in the professional activity uses various tools of the software. Development occurs not only in technology but also in the field of software. Thus, there is a situation when the teacher needs to monitor in due time the current trends of development of the software allowing to bring new ways of granting a teaching material. The main software tools in the field of education are multimedia software products. Electronic encyclopedias, reference books are widespread in the education system. Students increasingly use these software products in the learning process, which gives the opportunity to more deeply 
study the training material. Currently developed various software products that provide students the opportunity for self-study and self-development.

Multimedia software allows you to get set out the learning material, thereby systematizing students' knowledge. In situations when necessary multimedia material on the studied subject is absent, the teacher has an opportunity to independently prepare multimedia providing. For example, development of the multimedia presentations is widespread in the sphere of the higher education. Lecturer, focusing on academic discipline, independently develops the presentation in which there is no excess information. The student gains a complex of necessary knowledge of the studied subject. Besides the multimedia product can be provided to the student for independent repeated studying and consolidate the passable material.

In system of distance learning programs of computer testing are widely used. The use of this software is caused by necessity to control students' knowledge. Computer testing can be presented in several options where the student may be asked to choose only right version of the answer to a task, multiple version of the answer, to specify the validity or falsehood of the statement. Despite the various options of implementation of computer testing in this method of educational process there is a number of shortcomings. Not always computer-based testing reflects the true knowledge of the students. In the course of passing of remote testing the student can resort to different ways of searching the correct answer in third-party sources of information. Thus, at trained the purpose to pass test in any way without studying of educational material is formed. Development of the complex solution of the existing problems of computer testing remains a priority task.

It should be noted importance of existence in higher educational institutions of own databases to which access for students will be provided. It is known that the software is provided on a paid or free basis. It is important to provide free access of students to learning materials from information hubs of higher educational institutions. Free access of students to electronic libraries, electronic reference books and databases of higher educational institutions will allow trained to independently fill the gaps in the gained knowledge. The possibility of independent additional training is directed to realizing the potential of future expert.

Information technology and software cannot be introduced into the learning process without the material and technical base. Therefore it is important to understand that development of information technologies should affect also development of technological devices. For informatization of education, it is important to consider technological developments that may be embedded in the learning process.

At the present stage of development in higher educational institutions the specialized interactive presentation equipment is widely used. Electronic interactive whiteboards are one of the main representatives of modern technology. Using the interactive whiteboard is most clearly reflects the process of informatization of education. Thanks to the use of electronic interactive whiteboards effectively to bring into the study process modern technologies, by withdrawing electronic learning material, multimedia material to the electronic whiteboard. Presentation of information in this form allows you to more effectively apply learning material to students. The ability to use pre-prepared material significantly reduces the cost of teacher preparation time to the lesson. The interactive whiteboard allows involving all educational groups in educational process, thereby having interested students to knowledge acquisition. The projector to destination is similar to an interactive whiteboard. By means of a projector and special equipment the teacher can present students with pre-prepared material. The visual presentation of information promotes better assimilation of educational material. As the most modern technologies in education considered systems of interactive poll now. Such systems allow tracking the level of perception and understanding of educational material by students. Systems of interactive poll promote the solution of a number of tasks in the learning process. With this system it is possible to conduct a survey on the understanding of the content of the studied educational material, to exercise control of students' knowledge, to conduct interactive poll in order to identify the residual knowledge of the subject studied.

The considered technology, specialized software, modern technological advances provide the opportunity to effectively organize the educational process. At the same time it is necessary to understand that only complex use of all components will lead to effective informatization of education.

Prompt development of information technology entails not only great opportunities but also the need for continuous learning all sorts of technological innovations. Nowadays informatization of learning gives a real impetus to the development of the education system. Whatever the educational technology, they are based on the fundamental laws of pedagogy. Many experts should adapt to new tendencies, it is necessary will rethink the existing realities. The education system should not stand still; development of various spheres of activity should not take place without development of education. Also it is impossible to speak about efficiency only of e-learning or about efficiency only of traditional learning. It is necessary to speak about interaction of technologies of electronic training and traditional training. Traditional learning in its pure form does not always give an opportunity to immerse students in more advanced topics studied disciplines as limited opportunities can reveal only the basic theoretical principles. Being involved in an interactive learning process the student has the opportunity to gain a deeper knowledge of the issue under study. To what extent effective will be used one or another information technology in education depends on the skills of possession of the teaching staff of educational institution. In many respects development of information technologies is obliged to an education system. The specific of the education system is built in such a way that it is both a consumer and producer of information technology. Introduction of information technologies has 
had significant effect on system of traditional learning technologies. Modern methods of teaching with use of information technologies include the programmed learning, intellectual learning, expert systems, multimedia technologies and demonstration technologies. Each of the existing methods should perform the specific tasks of the educational process. Depending on the learning objectives, learning situations need to use one or the other learning technology. Information technologies allow to carry out the deep analysis of requirements trained, the analysis of the gained knowledge of a learning material.

The considerable attention is paid to the perspective directions of development of information technologies in interaction with pedagogical strategy. Development of the system of open access to learning materials is one of the priorities of the education informatization. The question of interaction, exchange of knowledge and experience in the specialized social services remains open. Many of the existing services do not interact with the educational system, thereby reducing the amount of accumulated resources that might be used in the learning process.

Creating a specialized environment of collective creativity and interaction in the educational process also requires further development. Existing technology, including MediaWiki technology insufficiently effective used in the modern education system. Collective learning reveals new opportunities for receiving profound knowledge through creation of multidimensional models. On the basis of recent trends of development of the Internet there are great opportunities for collective participation in work on specialized projects by means of modern technical means and the modern software.

Creation of an open complex of multimedia materials, educational and methodical materials and educational services are the important perspective directions of development and informatization of education. New modern technology provides students with access to educational materials, not only to gain additional knowledge, but also to discuss the studied questions with other students who are engaged in studying of the same issues. The widespread use of computer-based testing, interactive technologies hobbies students have to find more solutions to the development of new information technologies.

Special attention should be paid to use in education mobile technology and mobile tools. With the development of mobile devices and mobile software, students have the opportunity to use new forms of education. The process of learning becomes more fascinating, more comfortable. Availability to use mobile technology, regardless of the location provides significant advantages. Mobile tools and mobile technology contribute to the expansion of the perception of the material, stimulate the memory of the learner and develop communication skills [5].

A promising direction is the development of education in the field of international cooperation and collaboration. The development of the education system, learning from experience, interaction in the sphere of scientific research can be achieved through new technologies of communication.

\section{Conclusions}

The main problem of informatization of education is lack of system approach to realization of this process. In most cases information technologies are used in higher education on their own initiative. The efficiency of using the teaching staff of information technology in the learning process is significantly different. Equipment of educational institutions means of technological achievements are also very different. Quality of the processing equipment used in educational institution and the software is not always at the highest level. The complex of the listed problems affects both the education system in general, and prerequisites of her subsequent development.

Nevertheless, efficiency of use in an education system of information technologies is obvious. With the implementation of information technology in the learning process not only managed to increase the intensity of the process of learning, but also improve the quality of the learners' knowledge [6]. Informatization of education promotes increase of activity learners in the course of knowledge acquisition. The process of learning becomes interesting and fascinating. In an education system there is a trend towards increasing introduction of new information technologies. The existing regulatory base allows making certain steps towards to development of an education system, improving the quality of education. In the modern world, it becomes difficult to imagine receiving learner's common cultural and professional competences, without the use of advanced specialized information technology. The most significant problem of development of a modern education system is integration of modern information technologies which can be introduced in the educational process in order to increase the quality of education.

\section{References}

1. A.P. Podlevskikh, E-learning with application of distance learning technologies, In 2012 International Conference «YEES 2012», 164-167 (2012)

2. E.V. Borisova, Transformation of higher education, In 2014 International Scientific-practical Conference «Educational environment today and tomorrow», p. 28-30 (2014)

3. S.A. Titov, Cloud of science, 1, 21-23 (2013)

4. T. Malinovski, T. Vasileva-Stojanovska, D. Jovevski, M. Vasileva, V. Trajkovik, JITE:Research, 14, 1-19 (2015)

5. S. Fuegen, TechTrends, 56, 49-53 (2012)

6. K. Pandey, Handbook of Mobile Teaching and Learning, In Expectations from future technologies in higher education, p. 829-834 (2015) 